\title{
Investigation of Effects of Cognitive Strategies and Metacognitive Functions on Mathematical Problem- Solving Performance of Students with or Without Learning Disabilities*
}

\author{
Ufuk Özkubata, Emine Rüya Özmen ${ }^{b}$
}

$\begin{array}{ll}\text { Received } & : 21 \text { February } 2021 \\ \text { Revised } & : 28 \text { February } 2021 \\ \text { Accepted } & : \text { 24 March } 2021 \\ \text { DOI } & : \text { 10.26822/iejee.2021.203 }\end{array}$

*This study is based on the Ufuk Özkubat's doctoral thesis presented to the Institute of Educational Sciences of Gazi University.

${ }^{a}$ Corresponding author: *Ufuk Özkubat, Special Education Department, Gazi University, Ankara Turkey

E-mail: ufukozkubat@gazi.edu.tr

ORCID: https://orcid.org/0000-0002-9626-5112,

bEmine Rüya Özmen Special Education

Department, Gazi University, Ankara, Turkey, .

E-mail: eruya@gazi.edu.tr

ORCID: https://orcid.org/0000-0002-0226-1672,

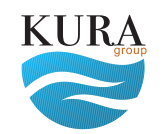

Copyright @

www.iejee.com

ISSN: 1307-9298

(C) 2021 Published by KURA Education \& Publishing. This is an open access article under the CC BYNC- ND license. (https://creativecommons.org/ licenses/by/4.0/)

\begin{abstract}
The purpose of this study was to examine the effects of cognitive strategies and metacognitive functions of students with learning disabilities (LD), students with lowachieving (LA), and students with average-achieving (AA) over their math problem-solving performance. The study sample consisted of 150 students with 50 students from each group. Study data were collected through ThinkAloud Protocols, Metacognitive Experiences Questionnaire, Math Problem Solving Assessment-Short Form, and 10 math problems. Study findings revealed that the significant predictors of math problem-solving performance were metacognitive strategies and experiences regarding students with LD, metacognitive strategies and knowledge considering students with LA, and metacognitive strategies in students with AA. A statistically significant relationship was found between problem-solving performance of students with LD and their metacognitive strategies and metacognitive experiences. Problem-solving performance and metacognitive strategies of students with LA were found to be close to a high level, and their metacognitive knowledge had a moderate relationship. It was also observed to be moderately related to problem-solving performance and metacognitive strategies in students with AA. The findings were discussed within the relevant literature scope, and suggestions were made for teachers in terms of implementation and researchers for further studies.
\end{abstract}

\author{
Keywords: \\ Cognitive Strategies and Metacognitive Functions, Learning \\ Disability, Math Problem Solving
}

\section{Introduction}

Problem solving is considered one of the basic skills in mathematics. Math problem solving includes combining and analyzing skills (Cawley \& Miller, 1986) and consists of one and/or more steps (Fuchs et al., 2004). It requires necessary calculation operations to be used in the solution process (Carpenter et al., 1993) and rarely contains irrelevant or distracting information (Passolunghi et al., 2005). The components of metacognition play a crucial role in math 


\section{iejee $\approx$}

problem-solving skills (Montague, 1992; Rosenzweig et al., 2011; Sweeney, 2010). Metacognitive knowledge describes what people know about what they know; metacognitive experience depicts who/what they are related to regarding the task or situation assigned to them, why they engage or withdraw from a task or event; while metacognitive strategy explains how they attempt to achieve an assigned task or situation (Sweeney, 2010). These three components refer to metacognitive functioning (Schudmak, 2014; Sweeney, 2010).

Students with LD experience limitations in combining the strategies they use in terms of metacognitive functions and use different strategies depending on their development (Geary, 2010; Hanich et al., 2001). Accordingly, studies revealed that students with LD either lack the required strategies to succeed or do not use the strategies they have (Montague \& Applegate, 1993; Ostad \& Sorenson, 2007; Özkubat \& Özmen, 2018). Regarding the assigned tasks in problem solving, students with LD have problems visualizing the problem, understanding what is asked in the problem, deciding which method to use in problem-solving operations, and fulfilling the procedures to be followed in the process appropriately. Students with higher metacognitive functions exhibit more cognitive and metacognitive strategies than their peers. However, students with LD have limitations in terms of strategy use compared to their peers (Rosenzweig et al., 2011; Swanson, 1990; Sweeney, 2010).

Montague's mathematics problem solving model includes cognitive and metacognitive strategies and operations that master problem solvers know and use them effectively (Montague et al., 1993). Montague (1992) identifies seven cognitive operations required to solve the problem successfully and metacognitive operations that allow the use of these cognitive operations (Montague et al., 2000). The seven cognitive strategies in problem solving are reading, paraphrasing, visualizing, hypothesizing, estimating, computing, and checking strategies. Also, the cognitive operations used in the process are understanding, translating, transforming, planning, estimating, processing, and evaluating. The use of cognitive operations and strategies in problem solving plays a role in all stages, such as reading, reaching the solution, and checking solution and the process (Rosenzweig et al., 2011). The correct realization of cognitive operations playing a role in this process occurs through the correct use of cognitive strategies (Montague, 1992). Metacognitive strategies used in problem solving are self-instruction, self-questioning, self-monitoring, and metacognitive operations using strategy knowledge, use, and control (Montague, 1992). Students apply metacognitive strategies to regulate cognitive operations used in math problem solving, manage these operations and organize their problem-solving performance (Montague, 1992). Besides, students use metacognitive strategies to comprehend how strategies are implemented, develop effective strategies, and manage these process operations (Lucangeli \& Cabrele, 2006). Therefore, Flavell's metacognition theory and Montague's mathematical problem-solving model provide a theoretical framework for examining cognitive strategies and metacognitive functions in math problem solving process (Sweeney, 2010).

Montague's model was applied in the studies in which the cognitive and metacognitive strategies used by students with LD while solving a math problem (Montague \& Applegate, 1993; Ostad \& Sorenson, 2007; Rosenzweig et al., 2011; Swanson, 1990), and the cognitive and metacognitive strategies students used while solving problems were assessed through the elements of this model. These studies evaluated the metacognitive strategy dimension only. However, in order for metacognitive processes to be understood in all dimensions as strategy, knowledge, and experience and to explain the results, the interaction of the related dimensions with each other is needed (Efklides, 2006; Veenman et al., 2006).

However, only one study examined all dimensions of metacognitive functions (Sweeney, 2010). Comparing the metacognitive experience and knowledge of students with LD, LA, and AA and the metacognitive strategies they used in solving math problems, Sweeney (2010) examined the effects of these variables in students' performance while solving math problems. According to findings, students' math problem-solving performance was affected by the metacognitive strategies, experiences, and knowledge.

The purpose of this study was twofold: (a) examining the relationship between cognitive strategies and metacognitive functions that sixth-grade students with $L D, L A$, and AA use in solving mathematical problems, (b) determining the effects of their cognitive strategies and metacognitive functions over a math problem solving. Unlike Sweeney (2010), this study examined the cognitive strategy and was conducted with more participants. Thus, it is considered to contribute to both national and international literature in terms of analyzing the relationship between strategies and functions used in problem solving.

\section{Method}

\section{Research Design}

This paper adopted a descriptive relational survey model to determine the cognitive strategies and metacognitive functions used by sixth-grade students with LD, LA, and AA while solving math problems and identifying the relationship between the specified 
strategies and the use of functions (Karasar, 2014).

\section{Participants and Recruitment Process}

The sample consisted of sixth-grade students with LD and $L A$, and $A A$ who were studying in five different districts of Ankara, the capital city of Turkey. The criteria for selecting students with LD were: a) having a diagnosis of learning disability in the disability health board report, b) not having any additional deficiencies. The criteria for selecting students with LA were a) being in the lowest $25 \%$ of the class in terms of math skills due to the teacher interview, b) not having a diagnosis of any deficiencies. Also, considering both groups, having certain learning outcomes in the basic arithmetic operations dimension (being able to perform addition and subtraction with threeand four-digit numbers that require regrouping, with an accuracy rate of $80 \%$ ) was another criterion. The criterion for selecting students with AA was to be in the average $50 \%$ of the class in terms of math skills as a result of the teacher interview. The common criterion for all three groups was that they could analyze without spelling at the instructional level, with an accuracy rate of $90 \%-95 \%$.The schools and classes of the sixth-grade students with LD were determined to select the students meeting the above-mentioned criteria. The researchers visited advisory teachers at the affiliated schools to determine whether their students met the aforementioned two criteria. Then, the math and Turkish-language teachers of those who fulfilled these two criteria were interviewed to identify students' knowledge of mathematics and reading. One-to-one assessments were conducted to obtain data on the students' math and reading prerequisite skills. Legal permission was obtained from the students' families. Students with LA and A were selected from the determined classes. The math and Turkish-language teachers were reinterviewed, and students meeting these criteria were assessed in terms of math and reading skills. The recruitment process was carried out by the first researcher. A total of 150 students participated in the research, including students with LD $(n=50)$, students with LA $(n=50)$, and students with AA $(n=50)$. The group of students with LD included 16 females (32\%) and 34 males (68\%). The students with LA were 22 females (44\%) and 28 males (56\%). There were 24 females (48\%) and 26 males (52\%) in the group of students with AA.

\section{Data Collection Tools}

\section{Preparing Math Problems}

Math problems requiring addition and subtraction with different difficulty levels (easy, medium, and difficult) were used to apply the think-aloud protocols and the metacognitive experiences questionnaire and assess math problem-solving performance. Preparing math problems included the following four stages: a) creating a problem pool by using math problems taken from sixth-grade math books, b) classifying them in the problem pool according to difficulty levels, c) obtaining expert opinions about the difficulty levels of problems, and d) performing validity and reliability analyses of math problems. The item difficulty indexes of easy, medium and difficult questions were .66., .54 and .36 , respectively; item discrimination indices were $.76, .70$ and .34 , respectively; point double series correlations were $.66, .58$ and .33 , respectively.

Three problems with different difficulty levels were used to determine the cognitive, metacognitive strategies and experiences that participants use to solve the math problems. To identify students' math problem-solving performance, 10 math problems with medium difficulty level were used (Özkubat, 2019). These problems are included in the appendix.

\section{Think-Aloud Protocols}

Participants used think-aloud protocols to determine the cognitive and metacognitive strategies in solving math problems. A think-aloud protocol is a verbal performance-based assessment system where participants speak out everything they think and do during tasks like reading a text or solving a math problem (Rosenzweig et al., 2011). The think-aloud protocol-coding form was developed based on the math problem-solving model developed by Montague (2003) and was adopted by this research. The first part included students' demographic characteristics (code name, school, and class), date, and duration of the application (start and end time of the application). The second part included cognitive strategies, and the third part involved the student's metacognitive strategies during the problem solving. The think-aloud protocol-coding form and problems used during the implementation of the think-aloud protocols are listed in Appendix 1 and 2

\section{Metacognitive Experiences Questionnaire}

Metacognitive Experiences Questionnaire (MEQ) developed by Efklides (1999) was used to determine the metacognitive experiences of the participants. Each item involves a statement followed by the following 4-point Likert scale rating system: not at all (1), a little (2), enough (3), and very (4). The metacognitive experience scale aims to unveil students' thoughts about mathematics and consists of the following two sub-sections: prospective reporting and retrospective reporting. The prospective reporting (e.g., How familiar are you with this problem?; How frequently did you encounter such a problem in the past?; How much do you think you need to 'think' in order to solve the problem?; How muck do you think you need to use some rules in order to solve the problem?) and 


\section{iejee}

retrospective reporting (e.g., How much did you like this problem?; How difficult do you think the problem was?; How much did you have to 'think' in order to solve this problem?; How much did you you need to use some rules in order to solve this problem?) subsections consist of 12 and 11 items, respectively. The problems used during the implementation of the MEQ are listed in Appendix 3

The validity and reliability of Metacognitive Experiences Questionnaire were conducted in three stages: ensuring the linguistic validity of the scale and collecting and analyzing data. The 23-item scale was administered to 475 students. Three weeks later, testretest was performed with 60 students. To examine the reliability of the scale, a Cronbach alpha reliability analysis was conducted. The six-factor structure of the Turkish Form of the Metacognitive Experiences Questionnaire was analyzed in terms of DFA models, fit index values, Cronbach alpha, and test-retest reliability coefficients. The findings revealed that fit index values were acceptable for all problems with different difficulty levels, the models were verified, and the fit index values for easy problems, medium problems, and difficult problems were 4.53, 4.55, 4.56, respectively. Cronbach alpha and test-retest reliability coefficients varied between .70 and .89 for easy problems; 70 and .89 for medium problems; and .70 and .89 for difficult problems. These results were acceptable and indicated high-reliability coefficients (Özkubat \& Özmen, 2020).

\section{Math Problem Solving Assessment-Short Form}

Math Problem Solving Assessment-Short Form developed by Montague (1992) is a "Solve It!" based model. It is an informal tool used to identify students' weaknesses and strengths in solving math problems (Montague, 1992). Before using the form, the linguistic validity was ensured, expert opinion was obtained, and the scoring rubric was adapted. Metacognitive knowledge levels of the participants were measured through 16 open-ended questions of the Math Problem Solving Assessment-Short Form. Three questions were about reading for understanding; two questions were for re-expressing them using their sentences, two questions were for visualization, two questions were for hypothesizing, three questions were for estimating the answers, two questions were for computing, and two questions were for determining the math problem solving knowledge about the checking process. (e.g., As you read, how do you help yourself understand math story problems? What else do you do when you read math story problems?; How do you help yourself remember what the problem says?; What do you do to make a picture in your mind? Is there anything else you do when you visualize?; How do you use your plan to help you solve math word problems?; Estimation is making a prediction about the answer using the information in the problem. How does estimation help in solving math word problems?; What do you do when you compute answers to word problems?; How do you check that you have correctly completed a math word problem?).

\section{Problems for Determining Mathematics Performance}

Problems for determining mathematics performance were used to determine the effects of participants' metacognitive knowledge and experience and their cognitive and metacognitive strategies over math problem-solving performance. These are 10 math problems with medium difficulty levels requiring the use of addition and subtraction. The specified problems are included in the Appendix 4

\section{Data Collection and Scoring Procedures}

\section{Data Collection}

The data collection process for each variable is presented in Table 1.

The study data were collected by the first researcher. The researcher applied the measurement tools in Table 1 to ensure standard application conditions during the data collection process.

The data collection process was performed in five steps. In the first step, the Metacognitive Experiences Questionnaire was applied. The researcher asked the student to read the easy problem and complete the prospective reporting part of the questionnaire. He then instructed the student to read and solve the easy problem and fill in the retrospective reporting part. The same procedure was applied to medium and difficult problems. In the second step, a training session of the think-aloud protocol was held.

The think-aloud protocol was applied in two stages. In the first stage, the think-aloud protocol was introduced. The researcher explained the purpose of the research and informed the students about the importance of the think-aloud in understanding how students solve math problems. At this point, the researcher read the instruction about how to do the think-aloud protocol (Johnstone et al., 2006): "I am interested in how students solve problems, so I want to ask you to solve three problems for me and let me listen to how you solve them. I am not interested in the answer you come up with as much as how you are thinking about the problem. What you say is really important, so I am going to use a tape recorder to make sure I don't forget anything." Then, the researcher became a model for thinking aloud while solving a math problem. The researcher demonstrated behaviors such as selfquestioning, self-controlling, and self-monitoring through problems. Finally, the researcher asked the 
Table 1

Data Collection Process

\begin{tabular}{|c|c|c|c|}
\hline Order & Application sessions & Duration & Data collection process \\
\hline 1 & $\begin{array}{l}\text { Session of Metacognitive } \\
\text { Experiences Questionnaire }\end{array}$ & 30 minutes & $\begin{array}{l}\text { The researcher asked the participants to fill in the Metacognitive Expe- } \\
\text { riences Questionnaire before and after solving math problems at three } \\
\text { different difficulty levels (easy, medium, and difficult). }\end{array}$ \\
\hline 2 & $\begin{array}{l}\text { Training session of Think- } \\
\text { Aloud Protocols }\end{array}$ & 30 minutes & $\begin{array}{l}\text { The researcher modeled the participant over a problem with a medium } \\
\text { difficulty level in the process of think-aloud protocol and asked the par- } \\
\text { ticipant to solve two different problems with the same difficulty levels by } \\
\text { thinking aloud. }\end{array}$ \\
\hline 3 & $\begin{array}{l}\text { Application session of Think- } \\
\text { Aloud Protocols }\end{array}$ & 30 minutes & $\begin{array}{l}\text { The researcher applied the think-aloud protocol to the participant while } \\
\text { solving math problems at three difficulty levels. }\end{array}$ \\
\hline 4 & $\begin{array}{l}\text { Session of Math Problem } \\
\text { Solving Performance }\end{array}$ & 45 minutes & $\begin{array}{l}\text { The researcher assessed the math problem-solving performance of the } \\
\text { participant. }\end{array}$ \\
\hline 5 & $\begin{array}{l}\text { Session of Math Problem } \\
\text { Solving Assessment-Short } \\
\text { Form }\end{array}$ & 20 minutes & $\begin{array}{l}\text { The researcher assessed the metacognitive knowledge level of the par- } \\
\text { ticipant. }\end{array}$ \\
\hline
\end{tabular}

students to solve two math problems with a medium difficulty level using the think-aloud protocols. The students were allowed to practice thinking out loud while solving a math problem.

The researcher encouraged students to speak with appropriate volume and clarity while solving math problems. In the third step, the researcher applied the think-aloud protocol after he repeated the instruction given in the think-aloud protocol training. The researcher presented the problem and asked, "Are you ready to solve the problem?" After receiving the answer "I am ready" from the student, he started the application by saying, "Now I want you to solve the problem by thinking aloud." The researcher did not interfere with any operations that the students made wrong while solving the problem or the operations they had difficulty with. However, he warned students and said, "Please do not forget to think aloud," when the student did not perform the think-aloud for five seconds. Also, when the students paused, he used expressions that help the student keep thinking aloud, such as "What do you think right now? Well done, you think very well, keep thinking aloud." The same application was applied to other math problems with different difficulty levels. Fourth, the researcher carried out the problems for determining math performance. The researcher said, "I want you to solve the problems in the booklet for me, you can start when you are ready." After receiving the answer "I am ready" from the student, he asked the students to solve 10 problems with medium difficulty levels. Fifth, the researcher verbally asked 16 open-ended questions from the Math Problem Solving Assessment-Short Form. The questions were provided in written form so that the students could understand the questions more clearly. If the student's answers were not clear and understandable, the researcher asked other questions such as "Can you explain a little more? Can you give an example? Is there anything else you would like to add?" When the student hesitated during the answering process, the researcher used expressions that help the student continue the answering process, such as "Well done, you are providing very good information, please continue."

Scoring Procedures. This part presents the scoring of the data collection tools used for each variable.

\section{Scoring of the Metacognitive Experiences Questionnaire}

Metacognitive experiences questionnaire has the following items based on a 4-point Likert scale rating system: not at all (1), a little (2), enough (3), and very (4). The total score for each problem with different difficulty levels ranges from 23 to 92 points.

\section{Scoring the Think-Aloud Protocols}

The verbal data recorded during the think-aloud protocol were transcribed verbatim immediately after the interviews. The think-aloud protocols were qualitatively analyzed, and then converted into quantitative data. The verbalization used by the participants in solving the math problems was coded as cognitive and metacognitive. The frequencies of the strategies were calculated separately for the problems with different difficulty levels. Cognitive verbalization had the following seven codes: reading, paraphrasing, visualizing, creating hypotheses, estimating, computing, and checking. Metacognitive verbalization was separated into two groups: productive and nonproductive metacognitive verbalization. Productive verbalization included selfmonitoring, self-instruction, self-questioning, and self-correction statements/questions directly related to solving the problem (Rosenzweig et al., 2011). For 


\section{iejee}

example, these statements are "I need to re-read the question," "That's not possible. It cannot be division," and "What am I doing?" Nonproductive verbalizations have reflective features of the student in line with the following categories: calculator, comment, and affect (Sweeney, 2010). This verbalization includes statements such as "I don't know what to do," "I'm confused," and "I need a calculator." The coding system included seven cognitive and seven meta-cognitive codes.

\section{Scoring of the Problems for Determining Mathematics Performance}

Each correct answer was scored as 1, while the incorrect answer was scored as 0 . The total score obtained from problems for determining math performance ranged from 0 to 10.

\section{Scoring the Math Problem Solving Assessment-Short Form}

The audio-recordings were transcribed verbatim. The whole data were analyzed qualitatively and then converted into quantitative data. The total score to be obtained from the form varies between 0 and 45 points. The reading comprehension part was assessed over 9 points, the restating the problem in own words was assessed over 5 points, the visualization part was assessed over 6 points, the hypothesizing part was assessed over 5 points, the estimating part was assessed over 8 points, the computing part was assessed over 6 points, and the checking part was assessed over 6 points.

\section{Reliability}

Procedural reliability, transcript reliability, and interrater reliability were calculated. First, the application reliability was calculated for the training and application stages of think-aloud protocols and the metacognitive experience scale. Procedural reliability form was listed to include the application of the metacognitive experience scale and the training and application steps of think-aloud protocols, and a checklist was prepared. The observer is a research assistant in special education, who is at the dissertation phase. The following formula is followed to calculate procedural reliability: the number of observed behaviors is divided by the number of planned behaviors multiplied by 100. Procedural reliability was found $100 \%$ for the training and application stages of the think-aloud protocols and the application stage of the metacognitive experiences questionnaire.

Second, $30 \%$ of the data were calculated for transcript reliability, and it was made by a research assistant in special education, who is at all but dissertation phase of his doctoral study. The formula of "consensus/ (consensus + disagreement) $\times 100 "$ was used to calculate the transcript reliability. The transcriptions of the think-aloud protocols consisted of a total of 13,689 words. After examining original recordings and transcripts, the rater added 53 words. The transcript reliability was found $99.6 \%(13.689 /[13.689+53] \times 100)$. For the reliability of the Math Problem-Solving AssessmentShort Form, a total of 15,404 words were delivered to the rater who added 70 words after examining original recordings and transcripts. The transcript reliability was observed to be $99.5 \%(15.404 /[15.404+70] \times 100)$.

Third, the reliability of coding forms was calculated for the think-aloud protocols, the Math Problem Solving Assessment-Short Form, and math problem-solving performance. The raters were provided with data including at least one-third of the whole data (45 pieces). The rater who calculated the reliability of the Think-Aloud Protocols and the Math Problem Solving Assessment-Short Form was an instructor holding a Ph.D. degree in special education, and he was an expert in cognitive and metacognitive strategies. The researcher provided training to the rater. The researcher and the observer scored the data at the end of the training. The data were delivered to the rater if there was a $90 \%$ or above agreement. The inter-rater reliability was calculated using the formula of "consensus / (consensus + disagreement) $\mathrm{X} 100$ ". The inter-rater reliability value was found to be $98.4 \%$ for the think-aloud protocol (range between \%97-\%100) and $99.2 \%$ for the Math Problem-Solving Assessment-Short Form (range between $98 \%$ and $100 \%)$. The rater calculating the reliability of the Math Problem-Solving Assessment Short Form was a Ph.D. candidate research assistant in special education. When calculating the reliability of students' math problem-solving performance, the correct answers were marked as 1 and the wrong ones as 0. Fortyfive booklets containing signed forms and solutions to problems were given to the raters. The inter-rater reliability of math problem-solving performance was found to be $100 \%$.

\section{Data Analysis}

The effects of metacognitive functions of participants' math problem-solving performance was identified using multiple regression analysis and Fisher Zr analysis.

\section{Findings}

Table 2 presents the multiple regression analysis results regarding the effects of students' cognitive and metacognitive strategies when solving mathematical problems of different difficulty levels (easy, medium, and difficult) and their metacognitive experience and knowledge levels over students' math problemsolving performance. 
Table 2

The Effects of Students' Cognitive Strategy and Metacognitive Functions Over Their Math Problem-Solving Performance According to the Group Variable

\begin{tabular}{|c|c|c|c|c|c|c|c|}
\hline & Variable & B & $\begin{array}{c}\text { Constant } \\
\text { error }\end{array}$ & $\beta$ & $T$ & $p$ & Bilateral $r$ \\
\hline & Constant & -2.93 & 1.380 & & -2.12 & .040 & \\
\hline & Cognitive strategy & .120 & .125 & .083 & .954 & .345 & .309 \\
\hline & Metacognitive strategy & 2.51 & .618 & .543 & 4.055 & $.000^{*}$ & .803 \\
\hline \multirow[t]{3}{*}{ LD } & Metacognitive experience & .071 & .032 & .304 & 2.247 & $.030^{*}$ & .749 \\
\hline & Metacognitive knowledge & .001 & .078 & .002 & .018 & .986 & .157 \\
\hline & & & & $R=0.83$ & $R^{2}=0.69$ & $F=25.05$ & $p=.000^{*}$ \\
\hline
\end{tabular}

Equation: Problem solving $=-2.93+2.51^{*}$ Metacognitive strategy $+.071^{*}$ Metacognitive experience

\begin{tabular}{|c|c|c|c|c|c|c|c|}
\hline & Constant & -2.11 & 1.652 & & -1.28 & .208 & \\
\hline & Cognitive strategy & -.037 & .214 & -.02 & -.172 & .864 & .381 \\
\hline & Metacognitive strategy & 2.361 & .435 & .576 & 5.431 & $.000^{*}$ & .684 \\
\hline \multirow[t]{3}{*}{ LA } & Metacognitive experience & .054 & .029 & .203 & 1.832 & .074 & .503 \\
\hline & Metacognitive knowledge & .195 & .087 & .259 & 2.229 & $.031^{*}$ & .387 \\
\hline & & & & $R=0.77$ & $R^{2}=0.59$ & $F=16.09$ & $p=.000^{*}$ \\
\hline
\end{tabular}

Equation: Problem solving $=-2.11+0.20^{*}$ Metacognitive strategy $+2.36 *$ Metacognitive knowledge

\begin{tabular}{|c|c|c|c|c|c|c|c|}
\hline & Constant & -1.62 & 6.363 & & -.254 & .801 & \\
\hline & Cognitive strategy & -.103 & .166 & -.08 & -.620 & .538 & .072 \\
\hline & Metacognitive strategy & 1.238 & .285 & .563 & 4.350 & $.000^{*}$ & .536 \\
\hline \multirow[t]{3}{*}{ AA } & Metacognitive experience & .110 & .087 & .157 & 1.266 & .212 & .155 \\
\hline & Metacognitive knowledge & .002 & .048 & .005 & .038 & .970 & .058 \\
\hline & & & & $R=0.57$ & $R^{2}=0.32$ & $F=5.31$ & $p=.001^{*}$ \\
\hline
\end{tabular}

Equation: Problem solving =-2.11+1.24* Metacognitive strategy

The metacognitive strategies that students with LD used when solving a math problem and their metacognitive experience levels were a significant predictor of math problem-solving performance $(F=25.05, p=.000<.05)$ and explained $69 \%$ of the variance. A high bilateral correlation value between math problem-solving performance and the use of metacognitive strategies $(r=0.80)$ and metacognitive experience ( $r=0.75$ ) was observed. The effect of using cognitive strategies and the level of metacognitive knowledge on math problem-solving performance was not statistically significant in students with LD. The LA students' metacognitive strategies used in solving math problems and their metacognitive knowledge levels were significant predictors of math problemsolving performance $(F=16.09, p=.000<.05)$ and explained $59 \%$ of the variance. The bilateral correlation value between math problem-solving performance and the use of metacognitive strategies was close to a high level $(r=0.68)$, and the bilateral correlation value between math problem-solving performance and metacognitive knowledge was moderate $(r=0.50)$. The effect of using cognitive strategies and the level of metacognitive experience on math problem-solving performance was not significant in students with LA. The AA students' metacognitive strategies used in solving math problems were a significant predictor of math problem-solving performance $(F=5.31, p=$
$.000<.05)$ and explained $32 \%$ of the variance. The bilateral correlation value between math problemsolving performance and the use of metacognitive strategies was moderate $(r=.54)$. The effect of using cognitive strategies and the level of metacognitive experience and knowledge on math problemsolving performance was not statistically significant in students with AA.

The multiple regression analysis results about cognitive strategies and metacognitive functions over students' math problem-solving performance showed differences according to the group variable. The Fisher $\mathrm{Zr}$ analysis for the stated differences is presented in Table 3 .

\section{Table 3}

Fisher Zr Analysis of Cognitive Strategies and Metacognitive Functions Over Students' Math Problem Solving According to the Group Variable

\begin{tabular}{ccc}
\hline Fisher $Z r$ & $\mathrm{LA}\left(R^{2}=0.59\right)$ & $\mathrm{AA}\left(R^{2}=0.32\right)$ \\
\hline $\operatorname{LD}\left(R^{2}=0.69\right)$ & 0.48 & $2.32^{*}(p=.03)$ \\
\hline $\operatorname{LA}\left(R^{2}=0.59\right)$ & ---- & 1.84 \\
\hline
\end{tabular}

${ }^{*} p<.05 ; z$ table value of .05 with $S D=50-3=47$ is 1.96 , and if the $z$ values are greater than the table value, it is significant. 
No statistically significant difference was observed between students with LD and LA $(Z=0.48, p>.05)$, and between low and average achievers $(Z=1.84, p$ $>$.05) in terms of the effect of cognitive strategy and metacognitive function levels on math problem-solving performance. Regression effects were found to be identical. However, a statistically significant difference between students with LD and AA was observed $(Z=$ $2.32, p<.05)$. Also, cognitive strategy and metacognitive function levels were found to have a higher effect on math problem-solving performance in students with LD.

\section{Discussion}

The effects of cognitive strategies and metacognitive functions over students' math problem-solving performance and their relationship levels were examined, and the findings were discussed. Several studies have examined the relationship between students' problem-solving performance and their metacognitive functions separately. These studies investigated the relationship between problem-solving and metacognitive strategies (Desoete, 2009; Desoete et al., 2006; Küçük-Özcan, 2000; Özsoy, 2005; Pape \& Smith, 2002), metacognitive knowledge and strategies (Carr et al., 1994; Davidson \& Sternberg, 1998; Schoenfeld, 1992; Wilson \& Clarke, 2002) as well as metacognitive experiences (Efklides, 2001; 2006; Efklides \& Petkaki, 2005). Also, Sweeney (2010) studied took metacognitive functions together and examined their effects and relationships on students' math problem-solving performance. Sweney found that metacognitive functions in all groups predicted participants' problem-solving performance. In this study, the predictors of math problem solving were metacognitive strategies and experiences in students with LD, metacognitive strategies and knowledge in students with LA, and metacognitive strategies in students with AA. Therefore, there is a correlation between the findings of the international literature and this research.

The fact that metacognitive strategies predicted math problem-solving performance in all groups could be explained by the nature of the problem-solving process, which is a metacognitive process based on the ability of students to examine and control their thoughts. The problem solver should be aware of the overall purpose of the process, the strategies that should be used to achieve this goal, and the effectiveness of these strategies. Therefore, during the problem-solving process, the student must control and monitor his/her cognitive process. These metacognitive strategies play a central role in the problem-solving process by controlling the other components of the problem-solving activities and regulating the relationship between them (Mayer, 1998; Özkubat \& Özmen, 2021; Özsoy, 2005). This result leads us to the teaching of metacognitive strategies. Thus, students should be informed about the metacognitive strategies used in solving math problems providing regulation and awareness of cognitive strategies (Montague, 2008). The problem solving applied in schools should be scrutinized as the metacognitive strategy was the variable predicting problem solving in all groups. The metacognitive dimension of both teaching and assessment processes is ignored in the problem-solving practices applied in schools (Çelik, 2017). Considering these practices, students use some cognitive strategies (i.e., reading, computing, and controlling) to solve problems, and these strategies are included problem-solving stages; however, how to implement the strategies is not modeled (Karabulut \& Özkubat, 2019; Özkubat \& Karabulut, 2021). Although these stages help students know how to solve problems, they do not focus on the metacognitive strategies used for self-monitoring and self-controlling (Özkubat et al., 2020). In particular, intervention to be implemented for students with LD with limitations in managing their cognitive processes is not possible with an instruction that lacks metacognitive strategies. The findings of this study support the instructional including metacognitive strategy elements to middle school students.

Like metacognitive strategies, metacognitive experience also predicted math problem-solving performance in students with LD. Metacognitive experience may be affected by factors such as willingness to solve problems, self-confidence, stress and anxiety, uncertainty, patience and perseverance, interest in problem solving or problem situations, motivation, and desire to show success (Akama, 2006). Many students with learning disabilities face failure in mathematics to develop negative attitudes toward learning mathematics and use their existing potential (Jonassen, 2003; Montague, 1997). This situation causes less frequent uses of strategies. Thus, when problem-solving interventions involving cognitive and metacognitive strategies are applied to students, their perceptions and attitudes toward the problem-solving process develop. Studies on cognitive and metacognitive strategies (Daniel, 2003; Montague, 1992; Whitby, 2009) draw attention to the relationship between attitude and the increase in the number of problem solving as well as strategy performance, advocating that different teaching strategies develop positive attitude and experience toward mathematics and math problems. Therefore, instead of directly teaching mathematical concepts and strategies to students, teachers should experience a strategy-teaching environment where students take an active role, self-monitor, and self-evaluate. Thus, students can develop their strategy repertoire by experiencing whether they can choose suitable strategies in the problem-solving process and whether the strategies they use work.

In addition to metacognitive strategies, metacognitive knowledge predicted math problem-solving 
performance in the students with LA. This may be explained by metacognitive strategies associated with metacognitive knowledge. The more information students have about the task assigned to them, the more they feel competent in completing the task. Thus, they are more persistent and use more strategies in completing the problem-solving process. On the contrary, if students have little knowledge, they will not insist on completing the assigned task and cannot use appropriate strategies. These reasons cause students to skip the necessary steps for the problem solution and negatively affect their understanding processes (Sweeney, 2010).

Comparing the effect of cognitive strategy and metacognitive function levels on students' math problem-solving performance, the findings of this study revealed that the effect of cognitive strategy and metacognitive function levels of students with learning disabilities on problem solving is higher than other students. The consensus is that the performance of students with LD can be developed significantly (Rosenzweig et al., 2011; Swanson, 1990; Sweeney, 2010). Therefore, the findings of this research underline the necessity of providing strategy teaching to students with learning disabilities to improve their cognitive and metacognitive function levels in solving math problems. Thus, students with LD will increase their strategy use, knowledge, and experience levels in problem-solving processes, just like their peers without LD. Therefore, there is a need for a process-based instruction for these students having problems in both cognitive and metacognitive functions, especially in increasing their math problem-solving performance (Karabulut \& Özmen, 2018). Interactive dialogues can be included in this teaching, and math problem-solving performance can be increased by providing effective and efficient use of strategies through graphic organizers and mnemonics (Güzel-Özmen, 2006).

Considering the research findings, there is a call for problem-solving interventions based on metacognitive functions for developing problem-solving performance of students with and without LD at middle school. Unlike previous studies, metacognitive functions were discussed together, not separately, in this paper. In addition to its contribution to the literature, this study still has some limitations. First, determining the cognitive and metacognitive strategies used by the participants in problem solving with think-aloud protocols is based on the assumption that the participants think aloud while performing a task. Therefore, there may be strategies that students cannot verbalize or use a verbalization technique that was inaccessible to the researcher. However, this research has more participants than previous studies using think-aloud protocols (Bannert \& Mengelkamp, 2008; Rosenzweig et al., 2011; Swanson, 1990; Sweeney, 2010). This is important in describing a more compre- hensive profile of students in different skill groups. Second, standard instruments were utilized to recruit the participants due to the lack of achievement tests in Turkey. However, using standard measurement tools can reduce heterogeneity within groups and offer better opportunities to detect differences. Finally, this research was conducted only with the sixth-grade students to examine problems requiring addition and subtraction skills at different difficulty levels. Therefore, further studies can examine different grade levels and different problem types. Despite these limitations, this research provides a ground for researchers and practitioners interested in identifying variables that play a role in problem solving. The findings of this study can be used to prepare math problem-solving intervention programs that include cognitive and metacognitive functions.

\section{References}

Akama, K. (2006). Relations among self-efficacy, goal setting, and metacognitive experiences in problem-solving. Psychological Reports, 98(3), 895-907. https://doi.org/10.2466/pr0.98.3.895907.

Bannert, M., \& Mengelkamp, C. (2008). Assessment of metacognitive skills by means of instruction to think aloud and reflect when prompted. Does the verbalization method affect learning? Metacognition and Learning, 3, 39-58. https:// doi.org/10.1007/s11409-007-9009-6.

Carpenter, T. P., Ansell, E., Franke, M. L., Fennema, E., \& Weisbeck, L. (1993). Models of problem solving: A study of kindergarten children's problemsolving processes. Journal for Research in Mathematics Education, 24(5), 428-441. https:// doi.org/10.2307/749152.

Carr, M., Alexander, J., \& Folds-Bennett, T. (1994). Metacognition and mathematics strategy use. Applied Cognitive Psychology, 8(6), 583-595. https://doi.org/10.1002/acp.2350080605.

Çelik, D., \& Güler, M. (2013). Examination of realistic problem solving skills of sixth grade students. Dicle University Journal of Ziya Gökalp Educational Faculty, 12(20), 180-195.

Daniel, G. E. (2003). Effects of cognitive strategy instruction on the mathematical problem solving of middle school students with learning disabilities. [Doctoral dissertation, Ohio State University].

Davidson, J. E., \& Sternberg, R. J. (1998). Smart problem solving: How metacognition helps. In Metacognition in Educational Theory and 


\section{iejee}

Practice (pp. 61-82). Routledge.

Desoete, A. (2009). Multi-method assessment of metacognitive skills in elementary school children: How you test is what you get. Metacognition and Learning, 3(3), 189. https:// doi.org/10.1007/s11409-008-9026-0.

Desoete, A., Roeyers, H., \& Huylebroeck, A. (2006). Metacognitive skills in Belgian third grade children (age 8 to 9) with and without mathematical learning disabilities. Metacognition and Learning, 1(2), 119-135. https://doi.org/10.1007/s11409-006-8152-9.

Desoete, A., \& Roeyers, H. (2002). Off-line metacognition: A domain-specific retardation in young children with learning disabilities? Learning Disability Quarterly, 25, 123-139. https:// doi.org/10.2307/1511279

Efklides, A. (1999). Feelings as subjective evaluation of cognitive processing: how reliable are they? Keynote address at 5th European Conference on Psychological Assessment, Patras, Greece.

Efklides, A. (2001). Metacognitive experiences in problem solving: Metacognition, motivation and self-regulation. In A. Efklides, J. Kuhl, \& R. M. Sorrentino (Eds.), Trends and prospects in motivation research (pp. 297-323). Kluwer.

Efklides, A. (2006). Metacognition and affect: What can metacognitive experiences tell us about the learning process? Educational Research Review, 1, 3-14. https://doi.org/10.1016/j. edurev.2005.11.001

Efklides, A., \& Petkaki, C. (2005). Effects of mood on students' metacognitive experiences. Learning and Instruction, 15, 415-431. https://doi. org/10.1016/j.learninstruc.2005.07.010.

Ericsson, K. A. \& Simon, H. A. (1980). Verbal reports as data. Psychological Review, 87, 215-251. https:// doi.org/10.1037/0033-295X.87.3.215.

Fuchs, L. S., Fuchs, D., Prentice, K., Hamlett, C. L., Finelli, R., \& Courey, S. J. (2004). Enhancing mathematical problem solving among third-grade students with schema-based instruction. Journal of Educational Psychology, 96(4), 635-647. https:// doi.org/10.1037/0022-0663.96.4.635.

Geary, D. C. (2010). Mathematical disabilities: Reflections on cognitive, neuropsychological, and genetic components. Learning and Individual Differences, 20(2), 130-133. https://doi. org/10.1016/j.lindif.2009.10.008.
Güzel-Özmen, R. (2006). The effectiveness of modified cognitive strategy instruction in writing on mildly mentally retarded Turkish students. Exceptional Children, 72, 281-294. https://doi. org/10.1177/001440290607200302.

Hanich, L. B., Jordan, N. C., Kaplan, D., \& Dick, J. (2001). Performance across different areas of mathematical cognition in children with learning difficulties. Journal of Educational Psychology, 93(3), 615. https://doi. org/10.1037/0022-0663.93.3.615.

Johnstone, C. J., Bottsford-Miller, N. A., \& Thompson, S. J. (2006). Using the think-aloud method (cognitive labs) to evaluate test design for students with disabilities and English language learners Minneapolis, MN: University of Minnesota, National Center on Educational Outcomes.

Jonassen, D. H. (2003). Using Cognitive Tools to Represent Problems. Journal of Research on Technology in Education, 35(3), 142-163. https:// doi.org/10.1080/15391523.2003.10782391.

Karabulut, A., \& Özkubat, U. (2019). Problem Solving. In Alptekin, S. (Eds), Mathematics in Special Education (pp. 263-293). Eğiten.

Karabulut, A., \& Özmen, E. R. (2018). Effect of "understand and solve!" strategy instruction on mathematical problem solving of students with mild intellectual disabilities. International Electronic Journal of Elementary Education, 11(2), 77-90. https://doi.org/10.26822/iejee.2018245314

Karasar, N. (2014). Research method. Nobel.

Küçük- Özcan, Z. Ç. (2000). Teaching metacognitive strategies to 6th grade students. [Master thesis, Boğaziçi University].

Lucangeli, D., \& Cabrele, S. (2006). The relationship of metacognitive knowledge, skills and beliefs in children with and without mathematical learning disabilities. In A. Desoete \& M. V. Veenman (Eds.), Metacognition in Mathematics Education (pp. 103-133) Nova Science.

Mayer, R. E. (1998). Cognitive, metacognitive and motivational aspects of problem solving. Instructional Science, 26, 49-63. https://doi. org/10.1023/A:1003088013286.

Montague, M. (1992). The effects of cognitive and metacognitive strategy instruction on mathematical problem solving of middle school students with learning disabilities. Journal of Learning Disabilities, 25(4), 230-248. https://doi. 
org/10.1177/002221949202500404.

Montague, M. (1997). Cognitive strategy instruction in mathematics for students with learning disabilities. Journal of Learning Disabilities, 30(2), 164-177. https://doi. org/10.1177/002221949703000204.

Montague, M. (2003). Solve it! A practical approach to teaching mathematical problem solving skills. Exceptional Innovations.

Montague, M. (2008). Self-regulation strategies to improve mathematical problem solving for students with learning disabilities. Learning Disability Quarterly, 31(1), 37-44. https://doi. org/10.2307/30035524.

Montague, M., \& Applegate, B. (1993). Middle school students' mathematical problem solving: An analysis of think-aloud protocols. Learning Disabilities Quarterly, 16, 19-32. https://doi. org/10.2307/1511157.

Montague, M., \& Applegate, B. (2000). Middle school students' perceptions, persistence, and performance in mathematical problem solving. Learning Disability Quarterly, 23(3), 215-227. https://doi.org/10.2307/1511165.

Montague, M., \& Dietz, S. (2009). Evaluating the evidence base for cognitive strategy instruction and mathematical problem solving. Exceptional Children, 75(3), 285-302. https://doi. org/10.1177/001440290907500302.

Montague, M., Applegate, B., \& Marquard, K. (1993). Cognitive strategy instruction and mathematical problem-solving performance of students with learning disabilities. Learning Disabilities Research and Practice, 8(4), 223-232. https://doi.org/10.1177/002221949703000204.

Montague, M., Warger, C, \& Morgan, H. (2000). Solve It!: Strategy instruction to improve mathematical problem solving. Learning Disabilities Research and Practice, 15(2), 110-116. https://doi. org/10.1207/SLDRP15027.

Ostad, A., \& Sorensen, P.M. (2007). Private speech and strategy-use patterns: Bidirectional comparisons of children with and without mathematical difficulties in a developmental perspective. Journal of Learning Disabilities, 40(1), 2-14. https://doi.org/10.1177/002221940704 00010101

Özdemir, İ. E., \& Pape, S. J. (2012). Supporting students' strategic competence: A case of a sixthgrade mathematics classroom. Mathematics
Education Research Journal, 24(2), 153-168. https://doi.org/10.1007/s13394-012-0033-8

Özkubat, U. (2019). An examination of the relationships between cognitive strategies and metacognitive functions used during mathematical problem solving by the students with learning disabilities, low achieving, and average achieving. [Doctoral dissertation, Gazi University].

Özkubat, U., \& Karabulut, A. (2021). Cognitive strategy instruction for mathematical problem solving in Kargın, T. Güldenoğlu, B. İ. (Eds), Teaching Mathematics in Special Education (pp. 142-171). Pegem Academy Publishing.

Özkubat, U., Karabulut, A., \& Özmen, E. R. (2020). Mathematical problem-solving processes of students with special needs: A cognitive strategy instruction model 'Solvelt!'. International Electronic Journal of Elementary Education, 12(5), 405-416. https://doi.org/10.26822/ iejee. 2020562131

Özkubat, U., \& Özmen, E. R. (2018). Analysis of mathematical problem solving process of students with learning disability: Implementation of think aloud protocol. Ankara University Faculty of Educational Sciences Journal of Special Education, 19(1), 155-180. https://doi. org/10.21565/ozelegitimdergisi.299494.

Özkubat, U., \& Özmen, E. R. (2020). Turkish adaptation of the metacognitive experiences questionnaire in solving math problems. OPUS International Journal of Society Researches, 16(31), 3958-3984. https://doi.org/10.26466/opus.736793.

Özkubat, U., \& Özmen, E. R. (2021). Determining the cognitive and metacognitive strategies used by students with learning disabilities and lowand average-achieving during mathematical problem solving. Ankara University Faculty of Educational Sciences Journal of Special Education, Advance Online Publication. https:// doi.org/10.21565/ozelegitimdergisi.736761

Özsoy, G. (2005). The relationship between problem solving skills and mathematical achievement. Gazi University Journal of Gazi Educational Faculty, 25(3), 179-190.

Özsoy, G. (2017). The effect of metacognitive strategy training on mathematical problem solving achievement. International Electronic Journal of Elementary Education, 1(2), 67-82. https:// Www.iejee.com/index.php/IEJEE/article/ view/278 


\section{iejee}

Pape, S. J., \& Smith, C. (2002). Self-regulating mathematics skills. Theory into Practice, 41(2), $93-$ 101. https://doi.org/10.1207/s15430421tip4102-5.

Passolunghi, M. C., Marzocchi, G. M., \& Fiorillo, F. (2005). Selective effect of inhibition of literal or numerical irrelevant information in children with attention deficit hyperactivity disorder (ADHD) or arithmetic learning disorder (ALD). Developmental Neuropsychology, 28, 731-753. https://doi.org/10.1207/s15326942dn2803-1.

Rosenzweig, C., Krawec, J., \& Montague, M. (2011). Metacognitive strategy use of eighthgrade students with and without learning disabilities during mathematical problem solving: a think-aloud analysis. Journal of Learning Disabilities, 44(6) 508-520. https://doi. org/10.1177/0022219410378445.

Choenfeld, A.H.(1992). Learning tothinkmathematically: Problem solving, metacognition, and sensemaking in mathematics. In D. Grouws (Ed.), Handbook for Research on Mathematics Teaching and Learning (pp. 334-370) MacMillan.

Schudmak, W. (2014). Metacognitive strategies employed during mathematical problem solving: a comparative case study of fifth graders who are gifted and have ADHD. [Doctoral dissertation, George Mason University].

Soydan, Ş. (2001). Development of instruments for the assessment of metacognitive skills in mathematics: an alternative assessment attempt. [Master thesis, Boğaziçi University].

Swanson, H. L. (1990). Influence of metacognitive knowledge and aptitude on problem solving. Journal of Educational Psychology, 82, 306-314. https://doi.org/10.1037/0022-0663.82.2.306.

Sweeney, C. M. (2010). The metacognitive functioning of middle school students with and without learning disabilities during mathematical problem solving. [Doctoral dissertation, University of Miami].

Veenman, M. V. J., Van Hout-Wolters, B. H., \& Afflerbach, P. (2006). Metacognition and learning: Conceptual and methodological considerations. Metacognition and Learning, 1(1), 3-14. https://doi.org/10.1007/s11409-0066893-0.

Whitby, P. J. S. (2012). The effects of Solve It! on the mathematical word problem solving ability of adolescents with autism spectrum
March 2021, Volume 13, Issue 4, 443-456

disorders. Focus on Autism and Other Developmental Disabilities 28(2) 78-88. https:// doi.org/10.1177/1088357612468764.

Wilson, J., \& Clarke, D. (2002). Towards the modelling of mathematical metacognition. Mathematics Education Research Journal, 16(2), 25-48. https://doi.org/10.1007/BF03217394.

Wong, B. Y. (1989). Cognitive and metacognitive aspects of learning disabled adolescents' composing problems. Learning Disability Quarterly, 12(4), 300-322. https://doi.org/10.2307/1510212. 
Appendix 1. Think Aloud Coding Sheet

\begin{tabular}{|c|c|c|c|c|c|c|c|}
\hline \multicolumn{8}{|c|}{ Cognitive Strategies } \\
\hline \multirow[t]{2}{*}{ Category } & \multirow[t]{2}{*}{ Operational Definition } & \multicolumn{2}{|c|}{ Problem 1} & \multicolumn{2}{|c|}{ Problem 2} & \multicolumn{2}{|c|}{ Problem 3} \\
\hline & & $F$ & $\%$ & $F$ & $\%$ & $F$ & $\%$ \\
\hline Reading & Reads the problem in its entirety & & & & & & \\
\hline Paraphrasing & Restates the problem in own words & & & & & & \\
\hline Visualize & $\begin{array}{l}\text { Use of images (diagrams, pictures, mental } \\
\text { imagery) to understanding task }\end{array}$ & & & & & & \\
\hline Hypothesizing & $\begin{array}{l}\text { Sets up a plan, decides on a solution path, sets } \\
\text { up a goal identifying operations to use }\end{array}$ & & & & & & \\
\hline Estimating & Predicts an answer & & & & & & \\
\hline Computing & Verbalizes computation & & & & & & \\
\hline Checking & $\begin{array}{l}\text { Checks steps are completed, information is } \\
\text { used, computations are accurate }\end{array}$ & & & & & & \\
\hline & Total & & & & & & \\
\hline \multicolumn{8}{|c|}{ Metacognitive Strategies } \\
\hline Category & Operational Definition & \multicolumn{2}{|c|}{ Problem 1} & \multicolumn{2}{|c|}{ Problem 2} & \multicolumn{2}{|c|}{ Problem 3} \\
\hline & & $F$ & $\%$ & $F$ & $\%$ & $F$ & $\%$ \\
\hline \multicolumn{8}{|c|}{ Non Productive Strategies } \\
\hline Calculator & Requests the use of a calculator & & & & & & \\
\hline Comment & $\begin{array}{l}\text { Statements of personal functioning during task } \\
\text { execution }\end{array}$ & & & & & & \\
\hline Affect & Statements concerning emotional disposition & & & & & & \\
\hline & Total & & & & & & \\
\hline \multicolumn{8}{|l|}{ Productive Strategies } \\
\hline Self-Correct & Corrects products of process errors & & & & & & \\
\hline Self-Instruct & Statements regarding procedural control & & & & & & \\
\hline Self-Monitor & Observes performance and progress & & & & & & \\
\hline Self-Question & Considers problem and solution path & & & & & & \\
\hline \multicolumn{8}{|c|}{ Total } \\
\hline & Grand Total & & & & & & \\
\hline
\end{tabular}

Appendix 2. The Problems and Their Difficulty Levels Used in The Think Aloud Protocol Implementations

Difficulty Levels of Problems

Easy

Moderate

Difficult
Problems

Rașit has 45, Cetin has 35, and Yunus has 55 walnuts. After Rașit eats 7, Cetin eats 8 , and Yunus eats 12 walnuts, all three of them give their remaining walnuts to their friend Ahmet. According to this, how many walnuts would Ahmet have?

The bill comes after three friends have eaten at the restaurant. When everyone pays $20 \mathrm{TL}$, the account will be paid, but because one of them has less money, the other two people have to pay 2 TL more each. Accordingly, how many TL does a person who has less money has?

There are 18 small fish and 4 large fish in an aquarium. Since 1 big fish eats 1 small fish every day, what will be the number of fish in the aquarium after 3 days?

Appendix 3. The Problems and Their Difficulty Levels Used in MEQ Implementations

\section{Difficulty Levels of Problems}

Easy

Moderate

Difficult

\section{Problems}

Ms. Naide receives a salary of $987 \mathrm{TL}$. She reserved $457 \mathrm{TL}$ for house rent, $100 \mathrm{TL}$ for butcher, $80 \mathrm{TL}$ for greengrocer, 75 TL for bills. How many lira is left for Ms. Naide?

Emel wants to read a 145-page book. On the first day, she reads 27 pages of the book. Since she read 25 more pages on the second day than the first day, how many more pages does she have to read to finish the book?

Mr. Ferhat, who liked a shirt worth 142 TL in February, pays 12 TL in advance. Since he will pay the rest in $10 \mathrm{TL}$ monthly installments, in which month will the installment end? 
Appendix 4. The Problems Used to Determine Mathematical Problem Solving Performance

Problems

1. In one hour, 40 bicycles, 30 cars, and 20 trucks passed through a street. Accordingly, how many are the total number of fourwheeled vehicles more than the total number of two-wheeled vehicles?

2. Asuman is 13 years old and his mother is 38 years old. How old was her mother when Asuman was 6 years old?

3. Hasan read 125 pages of the novel on Monday. He finished reading 17 more pages on Tuesday than Monday and 8 more pages on Wednesday. Accordingly, how many pages is the novel Hasan read?

4. The truck carrying parcels from Edirne to Iğdır unloaded 128 of 987 packages to Istanbul, 420 to Ankara and 235 to Erzurum. Accordingly, how many parcels were left in the truck when it came to Iğdır?

5. The entrance fee to an amusement park is $7 \mathrm{TL}$, the ferris wheel is $4 \mathrm{TL}$, the gondola and the fear train are $6 \mathrm{TL}$, and the bumper car is 4 TL. How many TL did Duygu, who went to the amusement park with such a price practice, spent a total of TL in the amusement park since she got on the ferris wheel and the fear train once?

6. Hacibayram Secondary School asked students to bring the books they read to be donated to the libraries of schools in our eastern provinces. On the 1st day 250 books, on the 2nd day 124 less than the number of incoming books of the 1st day, on the 3 rd day 179 more than the number of incoming books of the 2 nd day, and on the 4th day the total number of books received on the 2 nd and 3rd day were brought. Accordingly, how many books were collected in this school in 4 days?

7. Harun collected $478 \mathrm{~kg}$ of tea in the first day and $365 \mathrm{~kg}$ of tea in the second day in the tea garden. Since Harun collects as much tea as he did in the first two days on the 3rd day, how many $\mathrm{kg}$ of tea did he collect in these three days?

8. When a number is added 26 and subtracted 72 , it makes 136 . Find the number.

9. Osman's height is $17 \mathrm{~cm}$ shorter than his mother's. Osman's father is $25 \mathrm{~cm}$ taller than Osman. Since Osman's height is $145 \mathrm{~cm}$, what is the total height of his mother and father?

10. Semih has 35 marbels. Gökhan's number of marbles is 8 less than Semih's number of marbles, while Hakan's number of marbles is 15 more than Gökhan's number. How many marbles does three of them have in total? 